\title{
POROSITY IN CAST EQUIAXED ALLOY 718
}

\author{
R.A. Overfelt*, V. Sahai*, Y.K. $\mathrm{Ko}^{+}$, and J.T. Berry ${ }^{+}$ \\ * Space Power Institute \\ Auburn University \\ 231 Leach Center \\ Auburn, AL 36849 \\ +Department of Metallurgical and Materials Engineering \\ University of Alabama \\ Tuscaloosa, AL 35487
}

\begin{abstract}
Alloy 718 is a widely used superalloy which shows excellent performance at moderate temperatures. This desirable performance originates from the composition and processing conditions. Many manufacturers choose to investment cast Inconel 718 for their components because of investment casting's ability to produce complex parts at reasonable costs. However, improper casting conditions can cause deleterious defects to occur such as porosity. The prediction of the porosity distribution in shaped castings is a popular research topic at the present time. A number of semi-empirical criteria functions have been proposed to assist in such predictions, the functions being generally obtained from computer modeling of casting solidification. Although considerable attention has been given to the use of porosity criteria functions with aluminum based alloys, only limited consideration has been given to superalloy castings. Four sets of plate castings were investment cast under varying foundry conditions and the porosity distributions metallographically characterized. The castings were top poured and contained vertical $50.8 \mathrm{~mm}$ by $50.8 \mathrm{~mm}$ plates of the following thicknesses: $2.54,12.7$, and $25.4 \mathrm{~mm}$. A computer solidification model was developed for the castings and utilized to examine the effectiveness of various porosity criteria functions for predicting porosity. The computer model was shown to be effective in predicting unfed centerline shrinkage in the 25.4 $\mathrm{mm}$ thick plates. In addition, the predicted porosity trends of two widely used porosity criteria functions were shown to be consistent with the measured amounts of porosity in three of the four $12.7 \mathrm{~mm}$ thick plates. However, significant process variations, e.g. inclusion content, can dominate the development of porosity in castings and make the prediction of porosity an inexact science. These effects and the effective application of porosity criteria functions in predicting process parameters for alloy 718 casting are also discussed.
\end{abstract}

\footnotetext{
Superalloys 718, 625, 706 and Various Derivatives Edited by E.A. Loria

The Minerals, Metals \& Materials Society, 1994
} 


\section{INTRODUCTION}

Poor feeding of liquid metal through the interdendritic mush can often cause microporosity in vacuum cast superalloys. Microporosity is very detrimental to the stress rupture and fatigue properties of aerospace components and modern investment casting foundries strive to minimize, if not eliminate, this insidious and persistent defect. Although hot isostatic pressing is commonly employed to close pores, robust feeding systems that are designed to prevent the initial nucleation and growth of porosity are clearly preferred. Improved feeding systems can be designed with the help of sophisticated finite element models, but much additional research in mushy zone permeabilities, interdendritic feeding, and porosity formation remains to be done.

Bishop and Pellini ${ }^{1}$ reasoned that a minimum temperature gradient, $G_{\text {min }}$, must be established to feed interdendritic solidification shrinkage sufficiently to achieve a minimum radiographic standard for steel castings. Hansen and Berry ${ }^{2}$ extended this idea and initiated the concept of thermal criteria functions for predicting the presence of porosity in castings using computational solidification models. These researchers believed that once the thermal history of the interior of the casting could be predicted, the tendencies for shrinkage porosity could be evaluated using physically-based empirical criteria. Niyama et al $^{3}$ felt that the time available for feeding the shrinkage would also be important and modified Bishop and Pellini's minimum thermal gradient as $(G / \sqrt{d T / d t})_{\min }$ where $T$ is the temperature and $t$ is the time. Although the $(G / \sqrt{d T / d t})_{\text {min }}$ criterion (hercafter referred to as NUMS after the authors) has found widespread use in predicting dispersed porosity in the solidification of short-freezing-range steel castings, it has found only limited usefulness in long-freezing-range alloy systems. More recently, Lee $e t$ $a l^{4}$ showed that a more complex thermal parameter, $G t_{s}^{2 / 3} / V_{s}$ (herein referred to as $L C C$ ) where $V_{s}$ is the solidification front velocity and $t_{s}$ is the solidification time, gives excellent correlations with microporosity development in $12 \mathrm{~mm}$ plate castings of aluminum alloy A356.

The primary goal of this research effort was to evaluate the ability of the various criteria functions applied within a computer solidification model to predict the occurrence of porosity in alloy 718 plate castings.

\section{EXPERIMENTAL AND SIMULATION PROCEDURES}

Four sets of castings were poured at Howmet Corporation, Whitehall, $\mathrm{MI}$ and contained vertical $50.8 \mathrm{~mm}$ by $50.8 \mathrm{~mm}$ plates of the following thicknesses: $2.54 \mathrm{~mm}, 12.7 \mathrm{~mm}$, and 25.4 $\mathrm{mm}$. The geometry of the castings is shown in Figure 1a, which is the finite element mesh utilized in the computer simulations. The order of the three plates was reversed on the opposite side of the casting. The castings were poured at $1488^{\circ} \mathrm{C}$ under the conditions shown in Table I. The mold temperatures at pouring were measured by thermocouples in the molds. The nucleating facecoat is used by Howmet Corporation to ensure fine, equiaxed grains in structural castings.

Table I. Experimental Casting Variables and Models Used

\begin{tabular}{ccccc}
\hline $\begin{array}{c}\text { Casting } \\
\text { Designation }\end{array}$ & $\begin{array}{c}\text { Mold Temperature } \\
\text { at Pouring }\left({ }^{\circ} \mathrm{C}\right)\end{array}$ & $\begin{array}{c}\text { Mold } \\
\text { Facecoat }\end{array}$ & $\begin{array}{c}\text { Best Computer Simulation } \\
25.4 \mathrm{~mm} \text { Plate }\end{array}$ & $12.7 \mathrm{~mm}$ Plate \\
\hline A & 800 & Standard & Model 1 & Model 1 \\
B & 900 & Standard & Model 2 & Model 2 \\
C & 860 & Nucleating & Model 1 & Model 2 \\
D & 900 & Nucleating & Model 2 & Model 3 \\
\hline
\end{tabular}




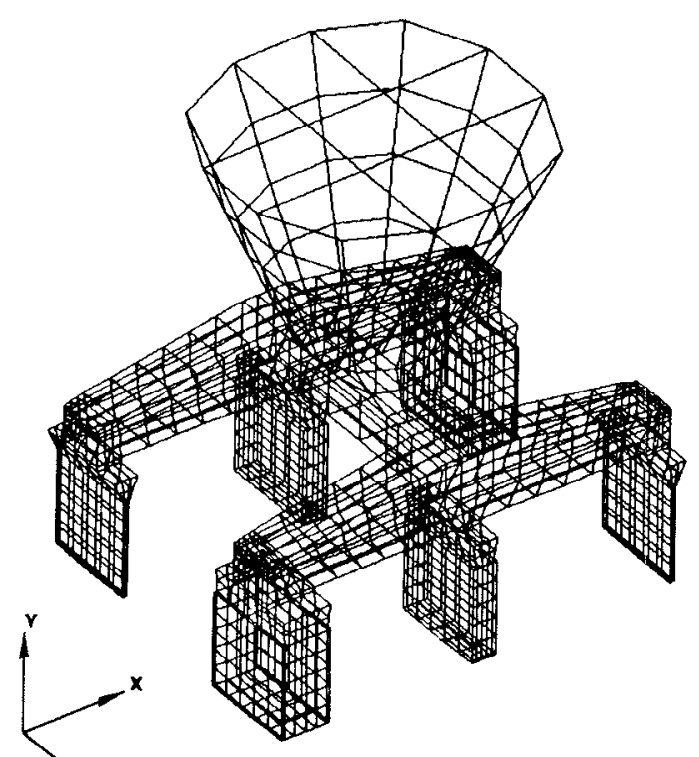

(a)

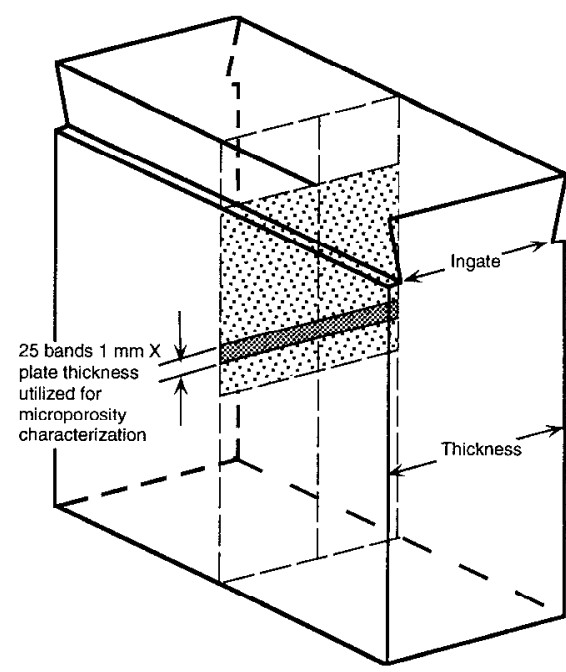

(b)

Figure 1. (a) Finite element mesh of the investment casting utilized in this study. Mold not shown. (b) Sectioning geometry for metallographic examination of the plates.

Standard metallographic procedures were used to section, grind, and polish samples for optical microscopy. Metallographic samples were prepared of the top half of each plate with the plane of observation being normal to the thickness direction as shown in Figure 1b. The porosity distribution in each as-polished sample was characterized using quantitative imaging techniques and the total percentage of porosity across each $1 \mathrm{~mm}$ wide band through the entire thickness of each plate casting is reported here. Only the 12.7 and $25.4 \mathrm{~mm}$ plates were investigated in this research since the $2.54 \mathrm{~mm}$ plates cooled too rapidly through the mushy zone for reliable calibration of the computer model.

The mold filling and casting cooling simulations were performed using the commercial finite element code ProCAST Version 2.2.1 running on a Sparcstation 10 computer. The finite element model was meshed using PATRAN as shown in Figure 1a at Howmet Corporation. The mold thickness was assumed to be a uniform $12.7 \mathrm{~mm}$ (not shown in Figure 1). Latent heat release was modeled by the enthalpy method to ensure that cooling rate effects on the temperature distribution of the latent heat were accurately incorporated. The thermophysical properties used in the model are shown in Table II. The molten metal was assumed to enter at the pour temperature of $1488^{\circ} \mathrm{C}$ and a velocity of $0.05 \mathrm{~m} / \mathrm{s}$. The castings were poured in vacuum and then air cooled. The melt was assumed to be free of dissolved gases and the effects of any gas rejection or mold reaction were not included in the simulations. Both radiation and free convection from the mold surfaces to the surrounding atmosphere were considered. The fraction-solid versus temperature relationship presented by Ko and Berry from actual castings at similar cooling rates was used to deduce the enthalpy curve shown in Figure 2.[5] No attempt was made to model the development of the grain structure in the castings in these simulations.

A major unknown in the computational analysis of any casting configuration is the temperature dependency of the interface contact conductance $\left(H_{c}\right)$ between the cooling metal and the mold. The interface contact conductance is used to model the resistance to heat flow that occurs due to (1) imperfect contact between the metal and the mold and (2) the formation of an air gap between the metal and the mold due to shrinkage of the casting. Research by numerous investigators has shown that $H_{c}$ can be significantly different throughout the cooling cycle as well as around the casting/mold interface due to changes in the way the solidifying and shrinking metal interacts with the mold[6-9]. To ensure that the model(s) developed here 
accurately reflected the cooling conditions of the casting, the following procedure was employed to determine the interface contact conductance. A given temperature dependency of $H_{C}$ was assumed based upon experience. The cooling model was started using the calculated temperature field after mold filling as the initial temperature conditions for the cooling analyses. Periodically during the cooling solution, the simulation was stopped and the temperatures of the center node in the $25.4 \mathrm{~mm}$ plate and in the $12.7 \mathrm{~mm}$ plate were compared to the appropriate thermocouple results. On the basis of the match, the $H_{c}(T)$ would be increased or decreased depending upon whether the model was overpredicting or underpredicting the experimentally measured temperatures, respectively. This process was continued until the end of solidification. Figure 2 shows the interface contact conductance data determined in this fashion and utilized in the final simulations.

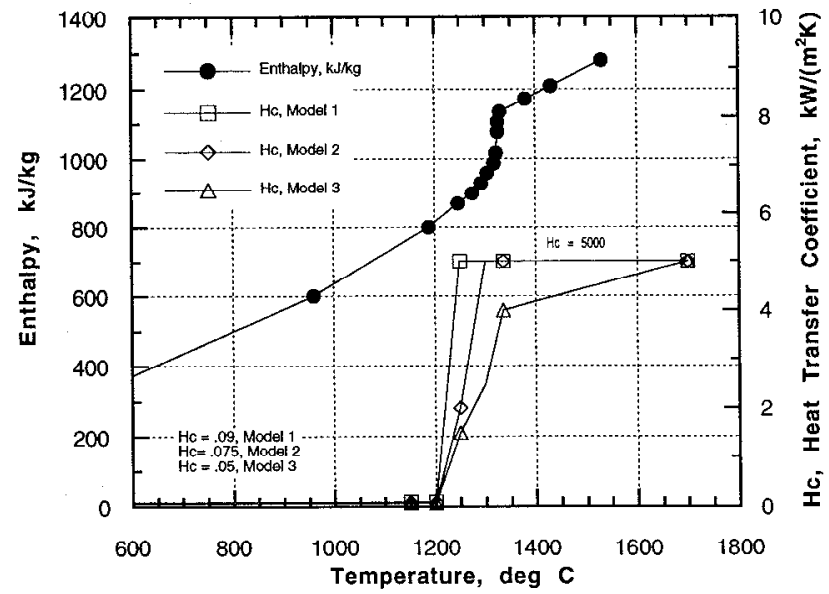

Figure 2. Enthalpy and interface contact conductance data used in the simulations.

Table II. Thermophysical and Related Properties Data

\begin{tabular}{|c|c|c|}
\hline Property & Inconel 718 & Mold \\
\hline Thermal conductivity, $\mathrm{W} / \mathrm{m}^{\circ} \mathrm{K}$ & 30.0 & 1.9 \\
\hline Specific heat, $\mathrm{kJ} / \mathrm{kg}^{\circ} \mathrm{K}$ & Figure 2 & 0.753 \\
\hline Density, $\mathrm{kg} / \mathrm{m}^{3}$ & 7,632 & 1,600 \\
\hline Surface tension, $\mathrm{Nt} / \mathrm{m}$ & 1.732 & NA \\
\hline Viscosity, Nt-sec/m² & 0.0045 & NA \\
\hline Total latent heat, $\mathrm{kJ} / \mathrm{kg}$ & $295 \mathrm{~kJ} / \mathrm{kg}$ & NA \\
\hline Emissivity & $\mathrm{NA}$ & 0.65 \\
\hline Liquidus temperature, ${ }^{\circ} \mathrm{K}$ & 1603 & NA \\
\hline Solidus temperature, ${ }^{\circ} \mathrm{K}$ & 1461 & NA \\
\hline Interface contact conductance, $\mathrm{kW} / \mathrm{m}^{20} \mathrm{~K}$ & (metal-mold: see Fig. 2) & (mold-air: 20) \\
\hline
\end{tabular}

\section{Porosity Characterization}

RESULTS

Figure 3 shows the average percentage porosity as a function of position downwards from the ingate for the $25.4 \mathrm{~mm}$ plates in each of the 4 castings. The $25.4 \mathrm{~mm}$ plates in castings "A" and "B" exhibited maximum porosity levels of $0.15 \%$ and $0.07 \%$, respectively. However, the $25.4 \mathrm{~mm}$ plates in castings " $\mathrm{C}$ " and " $\mathrm{D}$ " contained very low levels of porosity, exhibiting 
maximum values of only 0.01 and $0.03 \%$, respectively. The "A" and "B" castings were cast using the standard facecoat mold and the " $\mathrm{C} "$ and " $\mathrm{D}$ " castings were poured into molds with a nucleating facecoat. Figures $4 \mathrm{a}$ and $4 \mathrm{~b}$ show regions of centerline porosity from the $25.4 \mathrm{~mm}$ plates of the "B" and "D" castings, respectively. Large columnar grains can be seen extending from the left side in the "B" casting's $25.4 \mathrm{~mm}$ plate in Figure 4(a), whereas the grain structure is much more equiaxed (as expected from the nucleating facecoat) in the " $\mathrm{D}$ " casting.

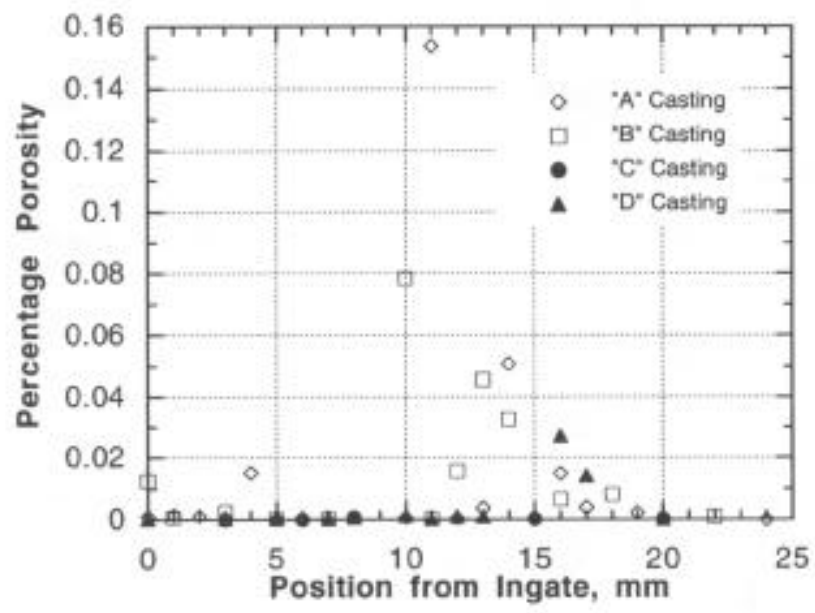

Figure 3. Porosity distribution from the $25.4 \mathrm{~mm}$ plates of each casting. (standard facecoat: A \& B; nucleating facecoat: C \& D)

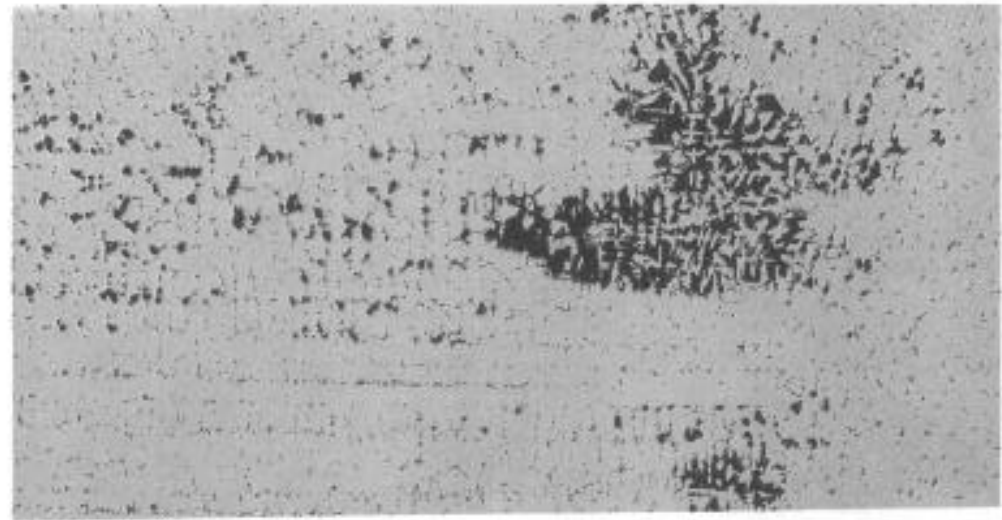

(a)

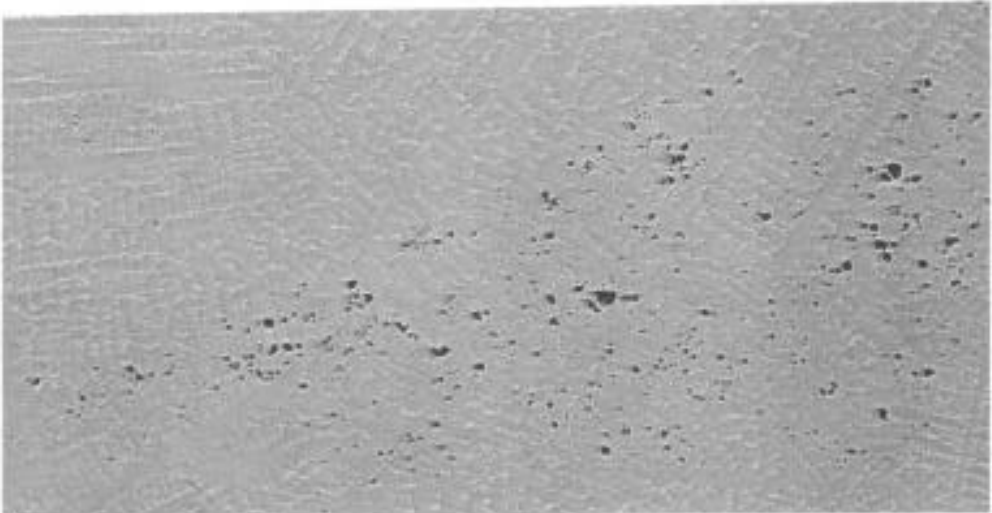

(b)
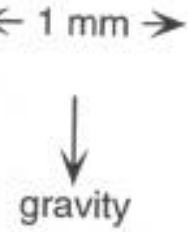

Figure 4. Typical centerline shrinkage of the (a) "A" and "B" castings and the (b) "C" and "D" castings. (25.4 $\mathrm{mm}$ thick plates, as polished) 
Figure 5 shows the average percentage porosity as a function of position downwards from the ingate for the $12.7 \mathrm{~mm}$ plates in each of the 4 castings. The $12.7 \mathrm{~mm}$ plate in casting "B" exhibited much higher porosity levels than the same plate from castings "A," "C," or "D." Figure 6 shows a region of extensive porosity in the $12.7 \mathrm{~mm}$ plate from the "B" casting. The shape of the porosity is highly irregular and concentrated in the interdendritic regions. Scanning electron microscopy and energy dispersive $\mathrm{x}$-ray analysis did not reveal detectable levels of nonmetallic inclusions in the " $\mathrm{B}$ " casting, although the possible presence or absence of folded thin oxide films could not be established. The porosity levels in the $12.7 \mathrm{~mm}$ plates from the "A," "C," and "D" castings were extremely low and consisted of isolated pores located in the interdendritic spaces. The type of mold facecoat utilized apparently did not exert a significant (or at least repeatable) influence on the development of porosity in the $12.7 \mathrm{~mm}$ thick plates as was seen in the $25.4 \mathrm{~mm}$ plates.

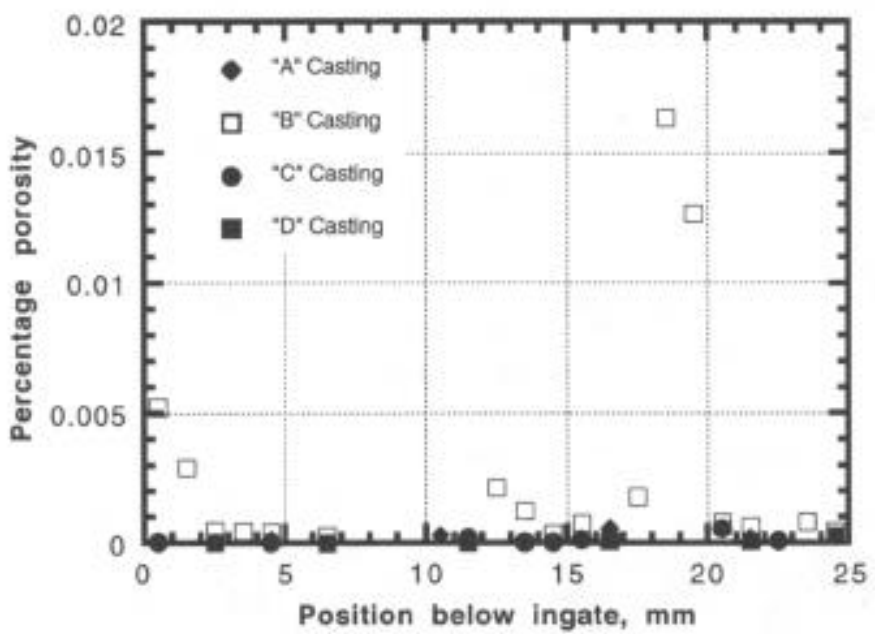

Figure 5. Porosity distribution from the $12.7 \mathrm{~mm}$ thick plates of each casting. (standard facecoat: "A" and "B"; nucleating facecoat: "C" and "D")

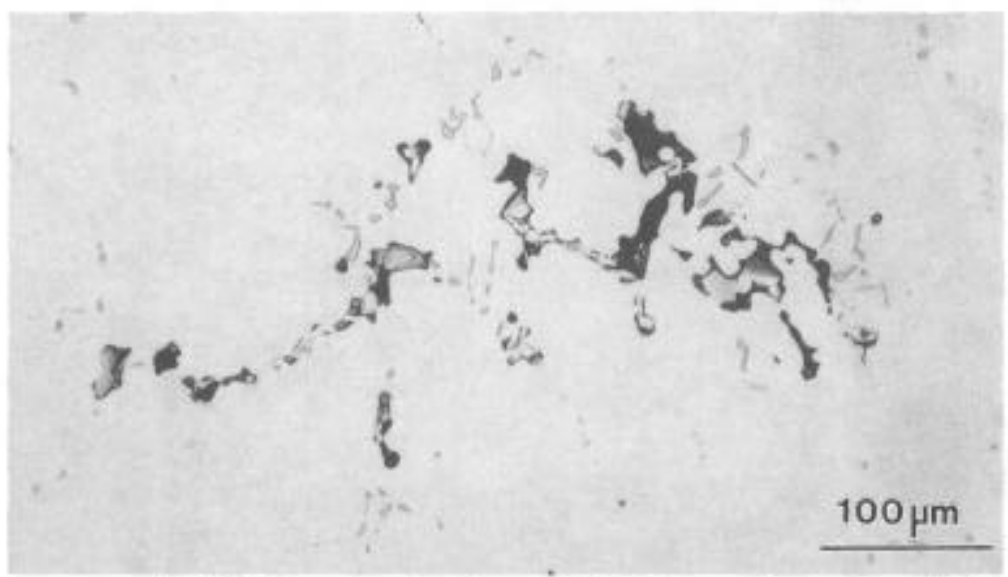

Figure 6. Interconnected shrinkage porosity from the $12.7 \mathrm{~mm}$ plate of the "B" castings. (as polished)

\section{Computational Simulation}

Figures $7 \mathrm{a}-7 \mathrm{c}$ show the mold filling sequence for the " $\mathrm{A}$ " simulation (Model 1). The pour cup fills, distributes metal into the horizontal crossarm, and on into the runners. The 50.8 $\mathrm{mm}$ X $50.8 \mathrm{~mm}$ vertical plates fill last. The predicted time to fill is approximately 2 seconds in agreement with the experiments. The run time for the mold filling simulation required 
approximately 4.6 hours. Figure $7 \mathrm{~d}$ shows the nonuniform temperature distribution at the end of fill due to cooling effects during filling. Note that the temperature field is not uniform as would be assumed if the mold filling simulation were not included in this analysis. In addition, increasing the mold temperature from $800^{\circ} \mathrm{C}$ to $900^{\circ} \mathrm{C}$ only increased the temperatures of the metal at the end of the mold fill simulation by less than $6^{\circ} \mathrm{C}$. Thus an initial mold temperature of $800^{\circ} \mathrm{C}$ was used in all simulations.

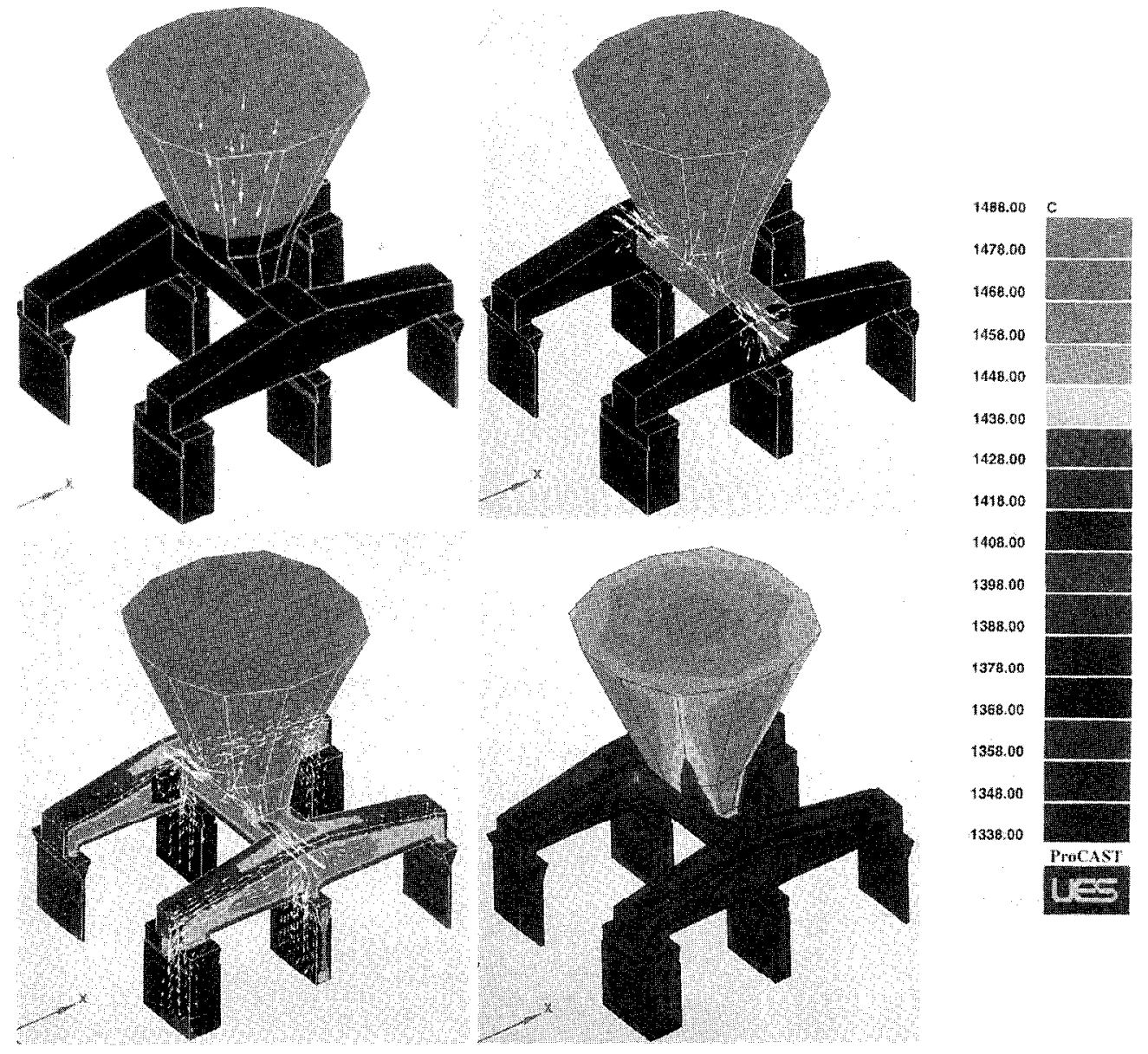

Figure 7. Mold filling simulation. (a) Pour cup filling, (b) metal distributing into the cross arm, (c) metal into the runners and the vertical plates, and (d) mold fill complete.

Figures 8 and 9 show the predicted and experimentally measured temperatures for the center of the $25.4 \mathrm{~mm}$ thick plate and $12.7 \mathrm{~mm}$ thick plate, respectively, cast under conditions "A, B, C, and D." Considering first the $25.4 \mathrm{~mm}$ thick plate (Figure 8), the agreement is good between Model 1's predicted temperatures and the measured temperatures from Molds "A" and " $\mathrm{C}$ " over the solidification range. For the $12.7 \mathrm{~mm}$ thick plate (Figure 9), the agreements between Model 1 and Casting "A", Model 2 and Castings "B" and "C", and Model 3 and Casting " $\mathrm{D}$ " are very good over the entire solidification range.

An important assumption for the application of criteria functions is that a flow path for moten metal from the riser must remain open to feed the shrinkage. Premature freeze-off, as often happens in isolated thick sections, invalidates the direct application of the criteria functions for predicting dispersed porosity. The total time to completely freeze is a very good indicator of such premature freeze-off in castings. Isolated areas with freeze times of local maxima represent regions that are unfed and will often exhibit gross centerline porosity as seen in Figure 4(a). Figure 10 shows the calculated times to completely solidify for the center of the $25.4 \mathrm{~mm}$ thick 
plate and the $12.7 \mathrm{~mm}$ thick plate as predicted by Model 1 . The $25.4 \mathrm{~mm}$ thick plate is predicted to exhibit a local freeze-times maximum in the interior of the plate. The Model 2 and Model 3 predictions of the calculated times to completely solidify were similar with respect to local maxima in the $25.4 \mathrm{~mm}$ plates, although not as definitively. Finally, for the $12.7 \mathrm{~mm}$ plates, no isolated maxima of the freeze times were predicted in any of the simulations. Thus these plates were predicted to solidify sequentially, a prerequisite for application of the microporosity criteria functions as described below.

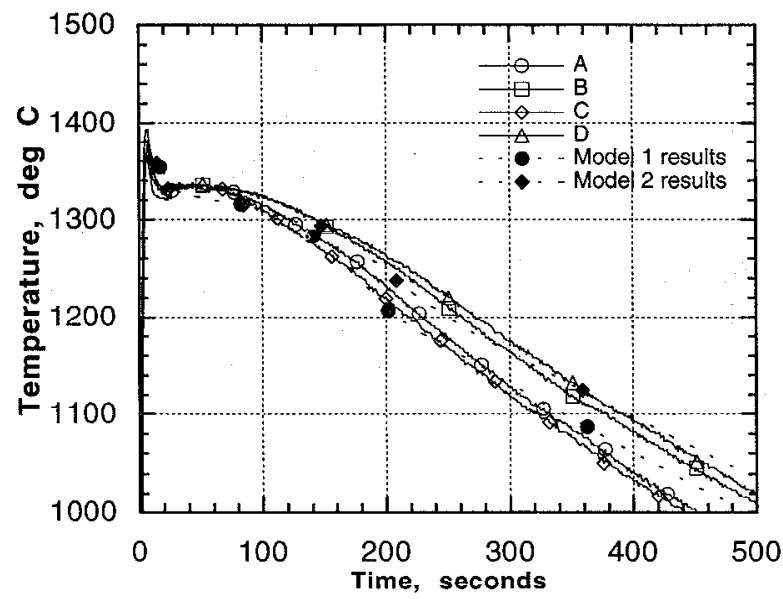

Figure 8. Comparison of experimental and predicted temperatures for the $25.4 \mathrm{~mm}$ thick plate cast under the indicated conditions. (Note Table I)

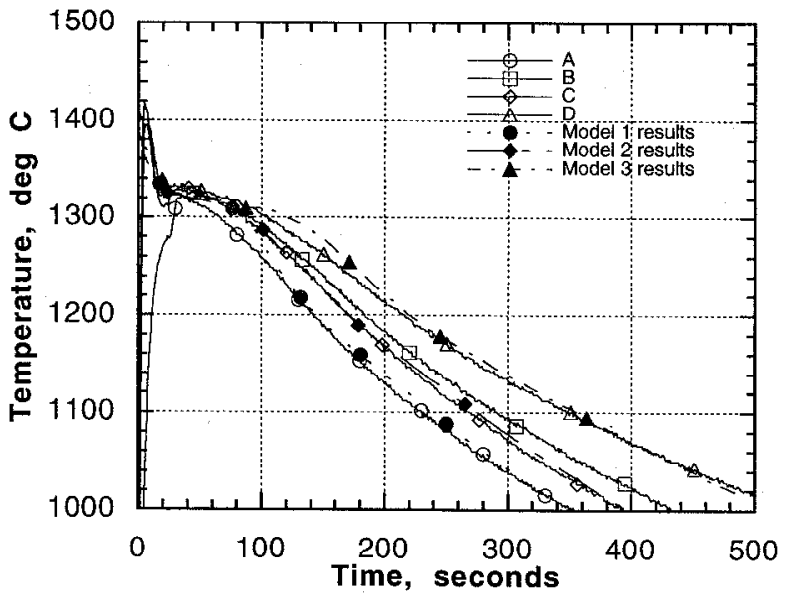

Figure 9. Comparison of experimental and predicted temperatures for the $12.7 \mathrm{~mm}$ thick plate cast under the indicated conditions. (Note Table I)

Computation of the various thermal parameters that make up the porosity criteria functions requires careful thought to ensure physically meaningful results. A critical temperature $\left(T_{c}\right)$ must be chosen for the computation of the thermal parameters. Since porosity is considered to nucleate near the end of solidification, much of the work in the literature considers the end of solidification as the critical moment to apply the analysis.[3,4] In this work the critical temperature was chosen to be the end of solidification, or $1188^{\circ} \mathrm{C}$. 


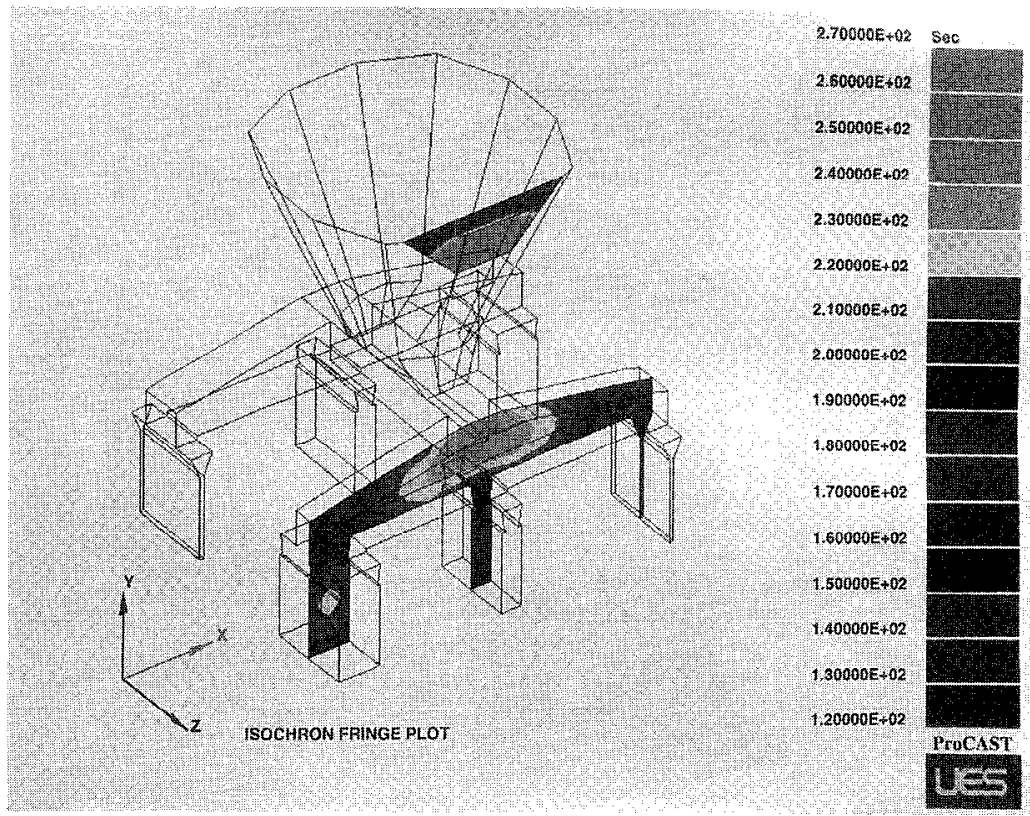

Figure 10. Computationally predicted times to completely freeze per Model 1.

When the temperature of each node in the casting model reached $T_{c}$, the total thermal gradient $G$ was evaluated by ProCAST using the temperatures and distances of each node's nearest neighbors. The solidification velocity $V_{S}$ (unfortunately labeled $R$ in the ProCAST manual) was evaluated by noting when cach node reached $T_{c}$, identification of a corresponding node some small distance away (in the direction of the total thermal gradient $G$ ) and then determination of the time required for the isotherm to reach that node. $V_{s}$ was simply calculated as that distance between the nodes divided by the time for the isotherm to reach it. The cooling rate was calculated in ProCAST by determining the time required for each node to cool between two arbitrary temperatures. The temperatures selected for this calculation were $1330^{\circ} \mathrm{C}$ and $1188^{\circ} \mathrm{C}$, the solidification range of alloy 718 . The local solidification time $t_{s}$ was simply the freezing range divided by the average cooling rate over the freezing range. The values of the thermal parameters thus determined were used to evaluate the NUMS and $L C C$ porosity criteria functions.

The values of the criteria functions indicate the relative tendencies of porosity formation throughout the casting. Higher values of NUMS (in steel castings) and LCC (in aluminum castings) usually indicate a lower tendency to form pores. Figures 11 and 12 show the computationally predicted NUMS and $L C C$ criteria functions for the region below the ingate of the $12.7 \mathrm{~mm}$ thick plate from castings "A," "C," and "D." The $12.7 \mathrm{~mm}$ plate from the "B" casting was considered an anomaly (see Discussion section) and was not included in the criteria function comparison due to the much larger amounts of porosity in the "B" casting. The total pore areas from the entire regions examined are also shown in Figures 11 and 12 for the 12.7 $\mathrm{mm}$ thick plate from the same three castings ("A," "C," and "D"). The total percentage porosities in these three plates varied from $4 \times 10^{-5}$ to $1.2 \times 10^{-4}$ percent, extremely low levels. Even at these very low amounts of total porosity, lower values of both the NUMS and the $L C C$ criteria functions are seen to correlate with higher values of porosity as observed in other alloy systems. Unfortunately, the low levels of porosity in these plates preclude a more definitive, statistically significant correlation between porosity and the thermal criteria functions. 


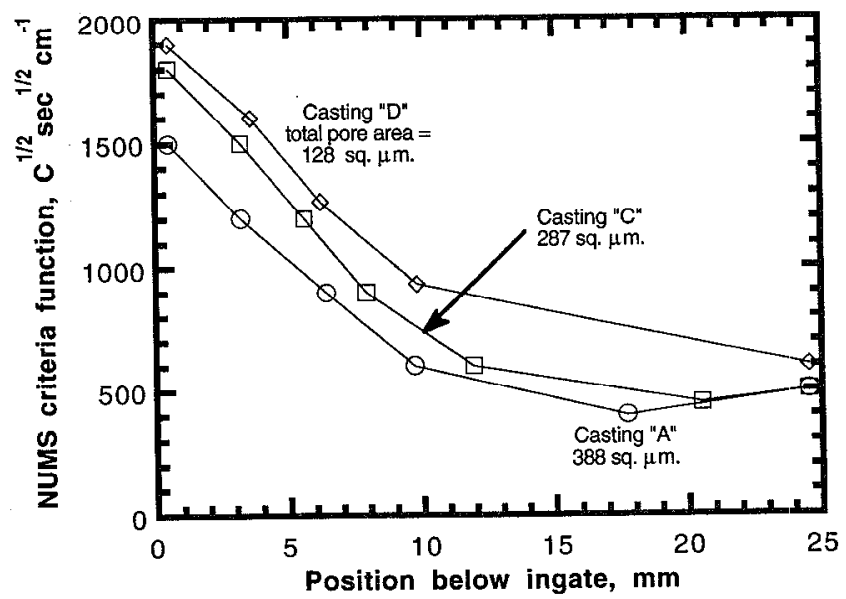

Figure 11. Calculated NUMS porosity criteria function for the $12.7 \mathrm{~mm}$ thick plate for the "A," "C," and "D" castings. Also shown is the total pore area from the entire region of the indicated castings.

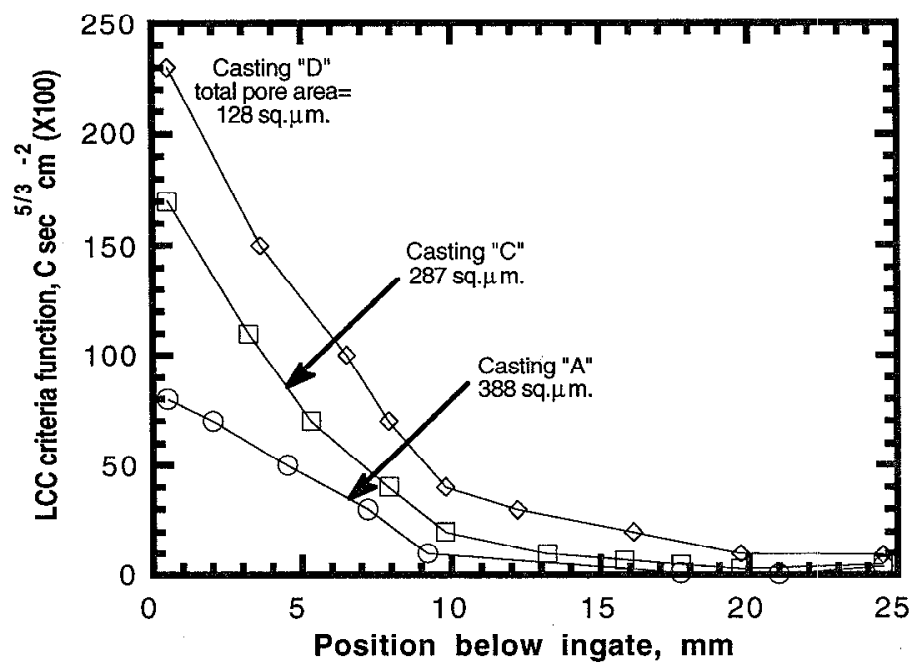

Figure 12. Calculated $L C C$ porosity criteria function for the $12.7 \mathrm{~mm}$ thick plate for the "A," "C," and "D" castings. Also shown is the total pore area from the entire region of the indicated castings.

\section{DISCUSSION}

In the above metallurgical and computational analyses of the freezing of the plate castings, thermally-based criteria functions have been shown to be inadequate in predicting low levels of porosity in the long freezing range superalloy alloy 718 . Even when computational models are carefully developed and painstakingly calibrated against relatively simple, three-dimensional production castings, popular porosity criteria functions are not reliable. 
The computational model(s) were carefully developed to ensure thermal equivalency between the model(s) and the test castings. The evolution of latent heat was incorporated using an enthalpy method that distributed the latent heat throughout the mushy zone in accordance with a previously measured solid fraction-temperature relationship at a similar cooling rate. Variations in interface contact conductance data were utilized in the models so that thermal equivalence was maintained for each of the different plate thicknesses even within the same casting. The temperature predictions from the models compared very well against actual thermocouple data from the instrumented test castings.

The major problem with direct application of the popular criteria functions is that microstructural variations from casting to casting can not be incorporated using current technology. Model 1 accurately described the thermal behavior of the $25.4 \mathrm{~mm}$ platc of castings "A" and "C" and and Model 2 accurately described the thermal behavior of the $25.4 \mathrm{~mm}$ plate of castings "B" and "D." Both Model 1 and Model 2 predicted premature freeze-off in the plate which is indicative of centerline shrinkage. Although aspects of centerline shrinkage were observed in the the $25.4 \mathrm{~mm}$ plate in all castings as predicted, those poured in molds with a standard facecoat ("A" and "B") exhibited significantly higher levels of porosity. Very much lower levels of centerline shrinkage developed in the castings poured into the molds with the nucleating facecoat and these castings also exhibited a more equiaxed microstructure. The more equiaxed microstructure apparently enabled a higher degree of feeding of the final solidification events. Thus microstructural effects participated directly in the development of porosity, but are not included in current computational simulations.

Pore formation in the $12.7 \mathrm{~mm}$ plates is more ambiguous. Each of the computational models, appropriate for the A (Model 1), B\&C (Model 2), and the D (Model 3) castings, predicted sequential solidification in the $12.7 \mathrm{~mm}$ plates. Thus the criteria functions should be applicable. The NUMS criterion developed by Niyama et al[3] and the $L C C$ criterion developed by Lee et al [4] both predicted increasing levels of porosity from the " $\mathrm{D}$ " casting through the " $\mathrm{C}$ " casting to the "A" casting, as was actually observed. However, these three castings exhibited very low levels of total porosity, e.g., on the order of $1 \times 10^{-4}$ percent. The "B" casting contained regions with a total porosity levels as high as $1.3 \times 10^{-3}$ percent, much higher than the others, but still extremely low. The higher levels of porosity in the "B" casting could not be predicted by the computational models. The " $\mathrm{A}$ " casting and the " $\mathrm{B}$ " casting were cast under similar conditions. The pouring temperatures were the same $\left(1488^{\circ} \mathrm{C}\right)$ and the mold facecoats were the same (standard facecoat). The only reported experimental difference was the higher mold temperature at pouring for the "B" casting $\left(900^{\circ} \mathrm{C}\right)$ as compared to the " $\mathrm{A}$ " casting $\left(800^{\circ} \mathrm{C}\right)$ and this was shown to produce negligible differences in metal temperatures during the mold filling simulations.

The development of porosity in metal castings is inherently a stochastic process since the presence of wetting nuclei are required for equiaxed grain formation and nonwetting nuclei are needed for the heterogeneous nucleation of pores $[9,10]$. Thus it appears that a larger sample size is required to obtain statistically significant correlations. In addition, the levels of dispersed porosity seen in the $12.7 \mathrm{~mm}$ plates are 2-3 orders of magnitude smaller than the levels utilized for the actual development of the porosity criteria functions [3,4]. These levels are probably so low that the formation of pores is extremely sensitive to minor microstructural variations from casting to casting. Incorporation of robust physical algorithms to predict porosity at such low levels may not be warranted.

\section{SUMMARY AND CONCLUSIONS}

Finite element modeling of equiaxed solidification is an effective tool for understanding much of the physics associated with porosity formation in alloy 718 castings. Thermally accurate models can be developed which provide significant assistance to foundries developing 
rigging designs. Local maxima of solidification times can be used to predict premature freezeoff and the resultant centerline shrinkage. In addition, the physically-based, semi-empirical NUMS and $L C C$ thermal criteria functions may be useful for predicting dispersed microporosity, but additional research is necessary to define their range of application.

Unfortunately, thermally accurate computer models today appear insufficient to predict porosity at the extremely low levels present in these castings. The ability of interdendritic fluid flows to feed the growing solid depends directly on the local metallostatic pressure and the grain structure/permeability of the dendritic mush. Thus the accurate and reliable prediction of porosity appears to require models that also predict the development of both grain structure and pressure fields. Work is in progress to extend the concept of thermal criteria functions to incorporate the important aspects of microstructure.[10] In addition, the presence (or absence) of non-wetting inclusions in the liquid metal can significantly affect the nucleation of pores under metallostatic tensile stresses. These effects will probably also have to be included.

\section{ACKNOWLEDGEMENTS}

The authors gratefully acknowledge the financial support received from NASA's Office of Advanced Concepts and Technology under Grant No. NAGW-1192 and from Howmet Corporation.

\section{REFERENCES}

1. H.F. Bishop and W.F. Pellini, "The Contribution of Riser and Chill Edge Effects to the Soundness of Cast Steel Plates," Trans. AFS, 5811950)185.

2. P.N. Hansen and J.T. Berry, "The Simulation of Heat Transfer in Casting and Weldments - Some Thoughts on Needed Research," Modeling of Casting and Welding Processes, H.D. Brody and D. Apelian, Eds. (Metallurgical Society of AIME,1981) p. 497.

3. E. Niyama, T. Uchida, M. Morikawa, and S. Saito, "A Method of Shrinkage Prediction and Its Application to Steel Casting Practice," Paper No. 10, 49th International Foundry Congress, Chicago, April 1982.

4. Y.W. Lee, E. Chang, and C.F. Chieu, "Modeling of Feeding Behavior of Solidifying Al-7Si-0.3Mg Alloy Plate Casting," Metall. Trans. B , $21 B$ (1990) 715.

5. Y.K. Ko and J.T. Berry, "Characterization of the Microstructure of Investment Cast Alloy 718," University of Alabama Department of Metallurgical and Materials Engineering Report, May 1993.

6. Y. Nishida, W. Droste, and S. Engler, "The Air-Gap Formation Process at the CastingMold Interface and the Heat Transfer Mechanism Through the Gap", Metallurgical Transactions, Volume 17B, 1986, pg. 833

7. K. Ho and R.D. Pehlke, "Metal-Mold Interfacial Heat Transfer," Metallurgical Transactions B, Volume 16B, 1985, pg.585.

8. H. Huang, V.K. Suri, J.L. Hill, and J.T. Berry, "Issues in Thermal Contact and Phase Change in Porosity Prediction," J. of Engrg. Matls. and Tech., Trans. of ASME, Vol 115, January 1993, pp. 2-7.

9. John Campbell, Castings (Oxford: Butterworth-Heinemann Ltd., 1991), p. 128.

10. R.A. Overfelt, "Cavity Nucleation During Microporosity Formation and Hot Tearing," submitted for publication, Metallurgical Transactions $B$.

11. V.K. Suri, A.J.Paul, N.H.El-Kaddah, and J.T. Berry, "Determination of Correlation Factors for the Prediction of Shrinkage in Castings - Part I - Prediction of Microporosity in Castings: A Generalized Criterion," Paper 94-138, accepted for presentation at the AFS 98th Casting Congress, May 1-4, 1994, Hamilton, Ontario 